\title{
Liver proteome of mice with different genetic susceptibilities to the effects of fluoride
}

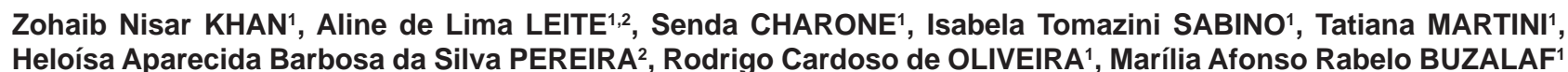

1- Universidade de São Paulo, Faculdade de Odontologia de Bauru, Departamento de Ciências Biológicas, Bauru, SP, Brasil.

2- Universidade Federal de São Carlos, Centro de Ciências Biológicas e da Saúde, Departamento de Genética e Evolução, São Carlos, SP, Brasil.

Corresponding address: Marília Afonso Rabelo Buzalaf - Departamento de Ciências Biológicas - Faculdade de Odontologia de Bauru - Universidade de São Paulo - Al. Octávio Pinheiro Brisolla, 9-75 - Bauru - SP - 17012-901 - Brazil - Phone: + 551432358346 - Fax + 551432271486 - e-mail: mbuzalaf@fob.usp.br

Submitted: August 13, 2015 - Modification: December 14, 2015 - Accepted: January 17, 2016

\section{ABSTRACT}

\begin{abstract}
A /J and 129P3/J mice strains have been widely studied over the last few years because they respond quite differently to fluoride (F) exposure. 129P3/J mice are remarkably resistant to the development of dental fluorosis, despite excreting less $F$ in urine and having higher circulating $\mathrm{F}$ levels. These two strains also present different characteristics regardless of $F$ exposure. Objective: In this study, we investigated the differential pattern of protein expression in the liver of these mice to provide insights on why they have different responses to F. Material and Methods: Weanling male A/J and 129P3/J mice ( $n=10$ from each strain) were pared and housed in metabolic cages with ad libitum access to low- $F$ food and deionized water for 42 days. Liver proteome profiles were examined using nLCMS/MS. Protein function was classified by GO biological process (Cluego v2.0.7 + Clupedia v1.0.8) and protein-protein interaction network was constructed (PSICQUIC, Cytoscape). Results: Most proteins with fold change were increased in A/J mice. The functional category with the highest percentage of altered genes was oxidation-reduction process $(20 \%)$. Subnetwork analysis revealed that proteins with fold change interacted with Disks large homolog 4 and Calcium-activated potassium channel subunit alpha-1. A/J mice had an increase in proteins related to energy flux and oxidative stress. Conclusion: This could be a possible explanation for the high susceptibility of these mice to the effects of $F$, since the exposure also induces oxidative stress.
\end{abstract}

Keywords: Proteomics. Fluorides. Liver. Oxidative stress.

\section{NTRODUCTI ON}

$\mathrm{A} / \mathrm{J}$ and $129 \mathrm{P} 3 / \mathrm{J}$ mice strains have been widely studied over the last few years because they respond quite differently to fluoride ( $F$ ) exposure. When given the same dose of $F$, the $A / J$ strain responds with a rapid onset and severe development of dental fluorosis, while the $129 \mathrm{P} 3 /$ J strain develops minimal fluorosis ${ }^{8}$. This was believed to be a consequence of the faster excretion of $\mathrm{F}$ by the 129P3/J strain. Surprisingly, a metabolic study showed that the 129P3/J mice excrete less $F$ in urine, have higher circulating $\mathrm{F}$ levels and, consequently, higher bone $\mathrm{F}$ levels, however, they still are remarkably resistant to the development of dental fluorosis 5 .

Some differences between these strains are intrinsic to themselves and do not depend on the $\mathrm{F}$ exposure. For example, the $\mathrm{A} / \mathrm{J}$ mice drink significantly higher volumes of water than their 129P3/J counterparts ${ }^{4}$, which can be explained by the increased expression of Alpha-aminoadipic semialdehyde dehydrogenase in the kidney of $129 \mathrm{P} 3 / \mathrm{J}$ mice, regardless of $\mathrm{F}$ exposure. This enzyme metabolyzes irreversibly betaine aldehyde to betaine that is the most effective osmoprotectant accumulated by eukaryotic organisms to cope with osmotic stress ${ }^{4}$. In addition, exclusive proteins expressed in the kidney of $\mathrm{A} / \mathrm{J}$ or $129 \mathrm{P} 3 / \mathrm{J}$ mice exhibited the same profile, regardless of $F$ exposure. This suggests that the genetic background per se accounts for such differences between these two strains of mice.

Liver represents the main detoxifying tissue in the body by processing, neutralizing, and 
eliminating toxins from the digestive tract through hepatocyte-mediated enzymatic detoxification systems. Due to these important functions, liver is one of the body's organs most subject to injury. Thus, it is believed that the differential pattern of protein expression in the liver of $\mathrm{A} / \mathrm{J}$ and $129 \mathrm{P} 3 / \mathrm{J}$ mice can provide new insights that could explain why they respond differently when exposed to F. To achieve this, state-of-the-art shotgun proteomics combined to bioinformatics approaches were used.

\section{MATERI AL AND METHODS}

\section{Animals and samples collection}

Weanling male mice from the $\mathrm{A} / \mathrm{J}$ and $129 \mathrm{P} 3 / \mathrm{J}$ inbred strains ( 3 -week-old; $n=10$ from each strain) were pared and housed in metabolic cages with ad libitum access to low-F food (AIN76A, PMI Nutrition, Richmond, IN, USA, $0.95 \mathrm{mg} / \mathrm{Kg} \mathrm{F}$ ) and deionized water for 42 days. The temperature and humidity in the climate-controlled room, which had a $12 \mathrm{~h}$ light/dark cycle, were $23 \pm 1^{\circ} \mathrm{C}$ and $40 \%-80 \%$, respectively. All experimental protocols were approved by the Ethics Committee for Animal Experiments of Bauru School of Dentistry, University of São Paulo (Protocol \# 031/2013). At the end of the study, the mice were anesthetized with ketamine/xylazine and livers were collected. Samples designated for proteomic analysis were stored at $-80^{\circ} \mathrm{C}$, while those designated for $\mathrm{F}$ analysis were stored at $-20^{\circ} \mathrm{C}$.

\section{Fluoride analysis in liver}

Fluoride analysis was done with the ion-sensitive electrode, after hexamethyldisiloxane-facilitated diffusion ${ }^{22}$, exactly as previously described ${ }^{20}$.

\section{Statistical analysis}

For liver F concentration, the GraphPad InStat software version 4.0 for Windows (GraphPad software Inc., La Jolla, California USA) was used. Data were analyzed by unpaired test $(p<0.05)$.

\section{Sample preparation for proteomic analysis}

Samples were prepared for analysis as previously described ${ }^{17}$. The frozen tissue was homogenized in a cryogenic mill (model 6770, Spex, Metuchen, NJ, EUA). For protein extraction, liver homogenate was incubated in lysis buffer containing $7 \mathrm{M}$ urea, $2 \mathrm{M}$ thiourea, 4\% CHAPS, 1\% IPG buffer pH 3-10, 40 mM DTT for $1 \mathrm{~h}$ at $4^{\circ} \mathrm{C}$ with occasional shaking. After this period, the homogenate was centrifuged at $15,000 \mathrm{rpm}$ for $30 \mathrm{~min}$ at $4^{\circ} \mathrm{C}$ and the supernatant containing soluble proteins was recovered. The proteins were precipitated using the kit PlusOne 2D Cleanup (GE Healthcare, Uppsala, Sweden), as recommended by the manufacturer. Pellets were resuspended in rehydration buffer ( $7 \mathrm{M}$ urea, 2
$M$ thiourea, $0.5 \%$ CHAPS, $0.5 \%$ IPG buffer $\mathrm{pH}$ 3-10, 18 mM DTT, 0.002\% bromophenol blue). Twenty-five $\mu \mathrm{L}$ of liver proteins from each animal of the same group were combined to constitute a pool that was centrifuged for clarification. To each pool, $50 \mathrm{mM} \mathrm{AMBIC,} \mathrm{containing} 3 \mathrm{M}$ urea, were added. Each sample was filtered twice in $3 \mathrm{kDa}$ AMICON (Millipore, St Charles, MO, USA). Protein quantification was measured in the pooled samples by Bradford protein assay ${ }^{3}$. To each sample $(50 \mu \mathrm{g}$ of total protein for each pool in a volume of $50 \mu \mathrm{L}$ ), $10 \mu \mathrm{L}$ of $50 \mathrm{mM} \mathrm{AMBIC}$ were added. In sequence, $25 \mu \mathrm{L}$ of $0.2 \%$ RapiGEST ${ }^{\mathrm{TM}}$ (Waters Co., Manchester, UK) were added and incubated at $80^{\circ} \mathrm{C}$ for $15 \mathrm{~min}$. Following, $2.5 \mu \mathrm{L}$ of $100 \mathrm{mM}$ DTT were added and incubated at $60^{\circ} \mathrm{C}$ for $30 \mathrm{~min}$. Also, $2.5 \mu \mathrm{L}$ of 300 mM IAA were added and incubated for $30 \mathrm{~min}$ at room temperature (under dark). Then, $10 \mu \mathrm{L}$ of trypsin (100 ng; Trypsin Gold Mass Spectrometry, Promega, Madison, USA) were added and digestion occurred for $14 \mathrm{~h}$ at $37^{\circ} \mathrm{C}$. After digestion, $10 \mu \mathrm{l}$ of $5 \%$ TFA were added, incubated for $90 \mathrm{~min}$ at $37^{\circ} \mathrm{C}$ and the sample was centrifuged $(14,000 \mathrm{rpm}$ for $30 \mathrm{~min})$. The supernatant was collected and $5 \mu \mathrm{L}$ of $\mathrm{ADH}(1 \mathrm{pmol} / \mu \mathrm{L})$ plus $85 \mu \mathrm{L} 3 \% \mathrm{ACN}$ were added.

\section{LC-MS/ MS and bioinformatics analyses}

Separation and identification of peptides were performed on a nanoAcquity UPLC-Xevo QTof MS system (Waters, Manchester, UK), exactly as previously described ${ }^{15}$. Difference in expression among the groups was obtained using PLGS software and expressed as $\mathrm{p}<0.05$ for downregulated proteins $1-p>0.95$ for up-regulated proteins (Table 1). Bioinformatics analysis was performed, as reported earlier ${ }^{1,15,17-19}$. Briefly, Uniprot protein ID accession numbers were mapped back to their associated encoding Uniprot gene entries for the comparison A/J X 129P3/J. Gene Ontology annotation of Broad Biological Process was performed using Cluego v2.0.7 + Clupedia v1.0.8, a Cytoscape plugin. Uniprot IDs were uploaded to Table 1 and analyzed with default parameters, which specify a Enrichment (right-sided hypergeometric test) correction method using Bonferroni step down, analysis mode "Function" and load gene cluster list for Mus musculus, Evidence Codes "All", set networking specificity "medium" (GO levels 3 to 8 ) and KappaScoreThreshold 0.03 . The proteinprotein interaction network was downloaded from PSICQUIC, built in Cytoscape version 3.0.2 and constructed as proposed by Millan ${ }^{18}$ (2013). A network was then created, providing global view of potentially relevant interacting partners of proteins whose abundances change. 
Table 1- Identified proteins with expression significantly altered in the liver of mice of group A/J control vs. 129 control (0 ppm F)

\begin{tabular}{|c|c|c|c|c|c|}
\hline \multirow[b]{2}{*}{${ }^{\text {aAccess }}$} & \multirow[b]{2}{*}{ Gene } & \multirow[b]{2}{*}{ Protein name description } & \multicolumn{3}{|c|}{ Foldchange } \\
\hline & & & $\begin{array}{l}\text { PLGS } \\
\text { score }\end{array}$ & $\begin{array}{c}\mathrm{A} / \mathrm{J} \\
0 \mathrm{ppm}\end{array}$ & $\begin{array}{c}\text { 129P3/ } \\
\text { J } 0 \text { ppm }\end{array}$ \\
\hline Number & name & & & & \\
\hline Q921H8 & Acaa1a & 3-ketoacyl-CoA thiolase A, peroxisomal & 195.3 & 1.65 & -1.65 \\
\hline Q8VCH0 & Acaa1b & 3-ketoacyl-CoA thiolase $B$, peroxisomal & 195.3 & 1.70 & -1.70 \\
\hline Q8BWT1 & Acaa2 & 3-ketoacyl-CoA thiolase, mitochondrial & 189.2 & 1,42 & $-1,42$ \\
\hline P63038 & Hspd1 & $60 \mathrm{kDa}$ heat shock protein, mitochondrial & 153.6 & 1.55 & -1.55 \\
\hline P20029 & Hspa5 & 78 kDa glucose-regulatedprotein & 254.4 & 1.43 & -1.43 \\
\hline P68033 & Actc1 & Actin, alpha cardiacmuscle 1 & 630.1 & 1.28 & -1.28 \\
\hline P68134 & Acta1 & Actin, alpha skeletalmuscle & 630.1 & 1.28 & -1.28 \\
\hline P62737 & Acta2 & Actin, aorticsmoothmuscle & 60.2 & 1.35 & -1.35 \\
\hline P60710 & Actb & Actin, cytoplasmic 1 & 62.4 & 1.25 & -1.25 \\
\hline P63260 & Actg1 & Actin, cytoplasmic 2 & 62.4 & 1.26 & -1.26 \\
\hline P63268 & Actg2 & Actin, gamma-enteric smooth muscle & 60.2 & 1.34 & -1.34 \\
\hline P47738 & Aldh2 & Aldehydedehydrogenase, mitochondrial & 72.6 & 1.67 & -1.67 \\
\hline P17182 & Eno1 & Alpha-enolase OS=Mus musculus & 129.4 & 1.46 & -1.46 \\
\hline P16460 & Ass 1 & Argininosuccinatesynthase & 58.6 & 1.28 & -1.28 \\
\hline P05202 & Got2 & Aspartateaminotransferase, mitochondrial & 79.3 & 1.34 & -1.34 \\
\hline Q03265 & Atp5a1 & ATP synthase subunit alpha, mitochondrial & 74.7 & 1.43 & -1.43 \\
\hline P56480 & Atp5b & ATP synthasesubunit beta, mitochondrial & 138.6 & 1.35 & -1.35 \\
\hline O35490 & Bhmt & Betaine--homocysteine S-methyltransferase 1 & 40.6 & 1.23 & -1.23 \\
\hline Q8C196 & Cps1 & Carbamoyl-phosphate synthase [ammonia], mitochondrial & 269.2 & 1.39 & -1.39 \\
\hline Q63880 & Ces3a & Carboxylesterase $3 \mathrm{~A}$ & 336.9 & 1.46 & -1.46 \\
\hline Q8VCU1 & Ces3b & Carboxylesterase 3B & 139.1 & 1.65 & -1.65 \\
\hline P24270 & Cat & Catalase & 260.8 & 1.62 & -1.62 \\
\hline Q8R0Y6 & Aldh1l1 & Cytosolic 10-formyltetrahydrofolate dehydrogenase & 53.1 & 1.55 & -1.55 \\
\hline Q9DCW4 & Etfb & Electron transfer flavoprotein subunit beta & 174.4 & 1.48 & -1.48 \\
\hline P10126 & Eef1a1 & Elongationfactor 1-alpha 1 & 245.5 & 1.39 & -1.39 \\
\hline P70694 & Akr1c6 & Estradiol 17 beta-dehydrogenase 5 & 207.5 & 1.48 & -1.48 \\
\hline Q91XD4 & Ftcd & Formimidoyltransferase-cyclodeaminase & 121.1 & 3.82 & -3.82 \\
\hline Q91Y97 & Aldob & Fructose-bisphosphatealdolase B & 96.1 & 1.62 & -1.62 \\
\hline P35505 & Fah & Fumarylacetoacetase & 136.0 & 1.46 & -1.46 \\
\hline P26443 & Glud1 & Glutamatedehydrogenase 1, mitochondrial & 467.9 & 1.84 & -1.84 \\
\hline P10649 & Gstm1 & Glutathione S-transferase Mu 1 & 129.1 & 1.26 & -1.26 \\
\hline P15626 & Gstm2 & Glutathione S-transferase Mu 2 & 109.8 & 1.32 & -1.32 \\
\hline P48774 & Gstm5 & Glutathione S-transferase Mu 5 & 109.8 & 1.32 & -1.32 \\
\hline P19157 & Gstp1 & Glutathione S-transferase P 1 & 317.2 & -0.66 & 0.66 \\
\hline P63017 & Hspa8 & Heat shock cognate $71 \mathrm{kDa}$ protein & 275.2 & 1.36 & -1.36 \\
\hline P01942 & $\mathrm{Hba}$ & Hemoglobinsubunit alpha & 1252.1 & -0.85 & 0.85 \\
\hline P02104 & Hbb-y & Hemoglobinsubunit epsilon-Y2 & 854.2 & -0.48 & 0.48 \\
\hline Q8CGP6 & Hist1h2ah & Histone $\mathrm{H} 2 \mathrm{~A}$ type $1-\mathrm{H}$ & 193.0 & 1.22 & -1.22 \\
\hline Q64522 & Hist2h2ab & Histone H2A type 2-B & 241.3 & 1.51 & -1.51 \\
\hline P62806 & Hist1h4a & Histone $\mathrm{H} 4$ & 88.1 & 1.54 & -1.54 \\
\hline P54869 & Hmgcs2 & Hydroxymethylglutaryl-CoAsynthase, mitochondrial & 292.1 & 1.22 & -1.22 \\
\hline P11588 & Mup1 & Major urinaryprotein 1 & 815.0 & -0.53 & 0.53 \\
\hline B5X0G2 & Mup17 & Major urinaryprotein 17 & 824.6 & -0.54 & 0.54 \\
\hline P11589 & Mup2 & Major urinaryprotein 2 & 815.0 & -0.54 & 0.54 \\
\hline P11591 & Mup5 & Major urinaryprotein 5 & 389.7 & -0.57 & 0.57 \\
\hline P02762 & Mup6 & Major urinaryprotein 6 & 815.0 & -0.53 & 0.53 \\
\hline P04938 & Mup8 & Major urinary proteins 11 and 8 (Fragment) & 815.0 & -0.54 & 0.54 \\
\hline P08249 & Mdh2 & Malatedehydrogenase, mitochondrial & 247.9 & 1.45 & -1.45 \\
\hline Q64374 & Rgn & Regucalcin & 107.2 & 1.36 & -1.36 \\
\hline P24549 & Aldh1a1 & Retinaldehydrogenase 1 & 208.9 & 1.49 & -1.49 \\
\hline
\end{tabular}




\begin{tabular}{|c|c|c|c|c|c|}
\hline \multirow{3}{*}{${ }^{\mathrm{a} A c c e s s}$} & \multirow{3}{*}{ Gene } & \multirow{3}{*}{ Protein name description } & \multicolumn{3}{|c|}{ Foldchange } \\
\hline & & & PLGS & A/J & 129P3/ \\
\hline & & & score & 0 ppm & J 0 ppm \\
\hline Number & name & & & & \\
\hline P07724 & Alb & Serumalbumin & 108.5 & 1.34 & -1.34 \\
\hline P00329 & Adh1 & Alcoholdehydrogenase 1 & 163.3 & + & - \\
\hline Q61234 & Snta1 & Alpha-1-syntrophin & 77.6 & + & - \\
\hline Q8VCT3 & Rnpep & Aminopeptidase B & 73.8 & + & - \\
\hline Q9D3D9 & Atp5d & ATP synthasesubunit delta, mitochondrial & 183.6 & + & - \\
\hline Q62210 & Birc2 & Baculoviral IAP repeat-containing protein 2 & 65.9 & + & - \\
\hline Bad & Q61337 & $\mathrm{Bcl} 2$ antagonist of cell death & 116.2 & - & + \\
\hline P21550 & Eno3 & Beta-enolase & 161.0 & + & - \\
\hline P34914 & Ephx2 & Bifunctionalepoxidehydrolase 2 & 441.9 & + & - \\
\hline Q8R1G2 & $\mathrm{Cmbl}$ & Carboxymethylenebutenolidasehomolog & 73.2 & + & - \\
\hline Q61686 & Cbx5 & Chromoboxproteinhomolog 5 & 96.9 & + & - \\
\hline Q3V079 & Ccdc176 & Coiled-coil domain-containing protein 176 & 66.5 & + & - \\
\hline P50172 & Hsd11b1 & Corticosteroid 11-beta-dehydrogenase isozyme 1 & 100.4 & + & - \\
\hline Cth & Q8VCN5 & Cystathioninegamma-lyase & 100.5 & - & + \\
\hline P48771 & Cox7a2 & Cytochrome $c$ oxidase subunit $7 \mathrm{~A} 2$, mitochondrial & 185.6 & + & - \\
\hline P10518 & Alad & Delta-aminolevulinicaciddehydratase & 316.8 & + & - \\
\hline Q9DBT9 & Dmgdh & Dimethylglycinedehydrogenase, mitochondrial & 89.4 & + & - \\
\hline Q99LC5 & Etfa & Electron transfer flavoprotein subunit alpha, mitochondrial & 77.6 & + & - \\
\hline Q9ER73 & Elp4 & Elongatorcomplexprotein 4 & 103.4 & + & - \\
\hline P63242 & Eif5a & Eukaryotic translation initiation factor $5 \mathrm{~A}-1$ & 104.8 & + & - \\
\hline Q9QXD6 & Fbp1 & Fructose-1,6-bisphosphatase 1 & 154.4 & + & - \\
\hline P17183 & Eno2 & Gamma-enolase & 159.3 & + & - \\
\hline Q3UHD2 & Gfod1 & Glucose-fructose oxidoreductase domain-containing protein 1 & 83.6 & + & - \\
\hline P11352 & Gpx1 & Glutathioneperoxidase 1 & 419.0 & + & - \\
\hline P24472 & Gsta4 & Glutathione S-transferase A4 & 127.0 & + & - \\
\hline Q9QYE6 & Golga5 & Golginsubfamily A member 5 & 103.4 & + & - \\
\hline P07901 & Hsp90aa1 & Heat shock protein HSP 90-alpha & 67.4 & + & - \\
\hline P11499 & Hsp90ab1 & Heat shock protein HSP 90-beta & 107.9 & + & - \\
\hline P68433 & Hist1h3a & Histone H3.1 & 163.6 & + & - \\
\hline P84228 & Hist1h3b & Histone H3.2 & 163.6 & + & - \\
\hline P84244 & Н3fЗа & Histone H3.3 & 163.6 & + & - \\
\hline P02301 & $H 3 f 3 c$ & Histone H3.3C & 163.6 & + & - \\
\hline Hgd & 009173 & Homogentisate 1,2-dioxygenase & 95.6 & - & + \\
\hline Hadh & Q61425 & Hydroxyacyl-coenzyme A dehydrogenase, mitochondrial & 183.9 & - & + \\
\hline Q5U5V2 & Hykk & Hydroxylysinekinase & 78.0 & + & - \\
\hline Q8BLR9 & Hif1an & Hypoxia-induciblefactor 1-alpha inhibitor & 96.3 & + & - \\
\hline 088844 & Idh1 & Isocitratedehydrogenase [NADP] cytoplasmic & 69.5 & + & - \\
\hline Q9CPU0 & Glo1 & Lactoylglutathionelyase & 203.5 & + & - \\
\hline P06151 & Ldha & L-lactatedehydrogenase A chain & 153.0 & + & - \\
\hline Acsl1 & P41216 & Long-chain-fatty-acid--CoA ligase 1 & 48.0 & - & + \\
\hline Q9DB40 & Med27 & Mediator of RNA polymerase II transcription subunit 27 & 68.9 & + & - \\
\hline Q8BPT6 & Immp2I & Mitochondrial inner membrane protease subunit 2 & 65.7 & + & - \\
\hline Myef2 & Q8C854 & Myelinexpressionfactor 2 & 44.9 & - & + \\
\hline Q9DC69 & Ndufa9 & $\begin{array}{l}\text { NADH dehydrogenase [ubiquinone] } 1 \text { alpha subcomplexsubunit } \\
9 \text {, mitochondrial }\end{array}$ & 79.2 & + & - \\
\hline Ncoa5 & Q91W39 & Nuclear receptor coactivator 5 & 67.7 & - & + \\
\hline P11725 & Otc & Ornithinecarbamoyltransferase, mitochondrial & 217.0 & + & - \\
\hline 008807 & Prdx4 & Peroxiredoxin-4 & 391.3 & + & - \\
\hline $\operatorname{Prdx5}$ & P99029 & Peroxiredoxin-5, mitochondrial & 174.7 & - & + \\
\hline O08709 & Prdx6 & Peroxiredoxin-6 & 321.1 & + & - \\
\hline P09411 & Pgk1 & Phosphoglyceratekinase 1 & 106.8 & + & - \\
\hline Pgap2 & Q3TQR0 & Post-GPI attachment to proteins factor 2 & 60.0 & - & + \\
\hline Prdm12 & A2AJ77 & PR domainzincfingerprotein 12 & 43.7 & - & + \\
\hline
\end{tabular}




\begin{tabular}{|c|c|c|c|c|c|}
\hline \multirow[b]{2}{*}{${ }^{\mathrm{a} A c c e s s}$} & \multirow[b]{2}{*}{ Gene } & \multirow[b]{2}{*}{ Protein name description } & \multicolumn{3}{|c|}{ Foldchange } \\
\hline & & & $\begin{array}{l}\text { PLGS } \\
\text { score }\end{array}$ & $\begin{array}{l}\text { A/J } 0 \\
\text { ppm }\end{array}$ & $\begin{array}{l}\text { 129P3/ } \\
\text { J } 0 \text { ppm }\end{array}$ \\
\hline Number & name & & & & \\
\hline Q80U40 & Rimbp2 & RIMS-bindingprotein 2 & 74.3 & + & - \\
\hline B2RY56 & Rbm25 & RNA-bindingprotein 25 & 80.8 & + & - \\
\hline Q91X83 & Mat1a & S-adenosylmethionine synthase isoform type-1 & 177.4 & + & - \\
\hline Q99J08 & Sec14I2 & SEC14-like protein 2 & 106.4 & + & - \\
\hline P47758 & Srprb & Signal recognition particle receptor subunit beta & 68.7 & + & - \\
\hline Hspa9 & P38647 & Stress-70 protein, mitochondrial & 119.8 & - & + \\
\hline Q8K2B3 & Sdha & $\begin{array}{l}\text { Succinatedehydrogenase [ubiquinone] flavoproteinsubunit, } \\
\text { mitochondrial }\end{array}$ & 74.3 & + & - \\
\hline Q62264 & Thrsp & Thyroid hormone-inducible hepatic protein & 180.0 & + & - \\
\hline P97360 & Etv6 & Transcriptionfactor ETV6 & 64.7 & + & - \\
\hline Tmem42 & Q9CR22 & Transmembraneprotein 42 & 110.6 & - & + \\
\hline Tpi1 & P17751 & Triosephosphateisomerase & 149.7 & - & + \\
\hline Q9D6F9 & Tubb4a & Tubulin beta- $4 \mathrm{~A}$ chain & 101.3 & + & - \\
\hline P68372 & Tubb4b & Tubulin beta-4B chain & 109.0 & + & - \\
\hline Ube2w & Q8VDW4 & Ubiquitin-conjugatingenzyme E2 W & 102.0 & - & + \\
\hline Q5QNV8 & Heatr9 & Uncharacterizedprotein C17orf66 homolog & 91.1 & + & - \\
\hline $\mathrm{N} / \mathrm{A}$ & Q8C4X7 & UPF0258 protein KIAA1024-like homolog & 38.4 & - & + \\
\hline P25688 & Uox & Uricase & 92.7 & + & - \\
\hline
\end{tabular}

The identified proteins are organized according to alphabetical order. Relative differential is indicated by + sign, when the protein is up-regulated and by - sign, when the protein is down-regulated in the respective comparison. aldentification is based on protein ID from UniProt protein database (http://www.uniprot.org/)

\section{RESULTS}

\section{Liver F analysis}

Mean \pm SD liver $F$ concentrations found in 129P3/] mice $(0.022 \pm 0.003 \mu \mathrm{g} / \mathrm{g})$ were significantly higher than those found in $A / \mathrm{J}$ mice $(0.015 \pm 0.002 \mu \mathrm{g} / \mathrm{g})$ $(t=4.929, p=0.0006)$.

\section{Liver proteome profile and identification of differentially expressed proteins \\ Table 1 shows proteins with expression changes in $\mathrm{A} / \mathrm{J}$ and $129 \mathrm{P} 3 / \mathrm{J}$ mice. In general, most proteins with fold change were increased in $A / J$ mice.}

\section{Gene ontology annotation}

Figure 1 shows the functional classification according to the biological process with the most significant term. Twelve categories were observed. Among them, the category with the highest percentage of genes was oxidation-reduction process $(20 \%)$, followed by cellular amino acid metabolic process (16\%) and response to oxidative stress (12\%).

\section{Protein-protein interaction network}

For the comparison displayed above, a network was created; employing all the interactions found in the search conducted using PSICQUIC. After the global network was created, nodes and edges were filtered using the specification for Mus musculus taxonomy (10090). The value of fold change and also the $p$-value were added in new columns. The ActiveModules 1.8 plug-in to Cytoscape was used to make active modules connected subnetworks within the molecular interaction network whose genes presented significant coordinated changes in fold changes and p-value, as shown in the original proteomic analysis. Figure 2 shows the subnetwork generated by VizMapper. As can be seen, most proteins with fold change present interaction with Disks large homolog 4 (Q62108; 11 proteins) and Calcium-activated potassium channel subunit alpha-1 (Q08460; 18 proteins).

\section{SCUSSI ON}

129P3/J mice interestingly have been reported to excrete less $F$ and as consequence to have higher circulating $F$ levels, bone and enamel $F$ levels and they still are remarkably resistant to

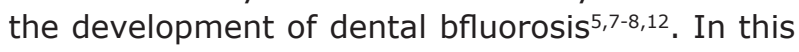
study, even without administration of $F$ through the drinking water and with consumption of a low-F diet, 129P3/J mice had significantly higher liver $F$ concentrations, which might have been due to the residual amounts of $F$ present in their diets and is in-line with the metabolic characteristics of this strain regarding $\mathrm{F}^{4-5}$.

In this study, proteomic analysis of liver of 129P3/J and A/J mice was employed to provide insights into the possible mechanisms that could 


\section{Strain A/J vs. $129 p 3 / J$}
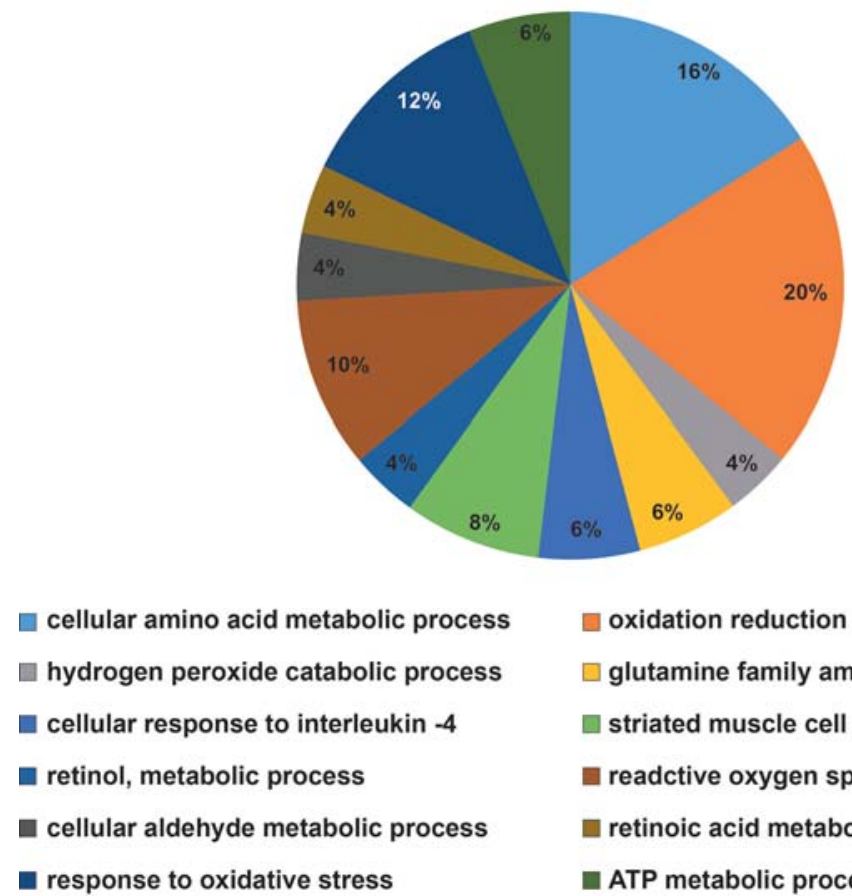

oxidation reduction process

$\square$ glutamine family amino acid metabolic process

n striated muscle cell development

readctive oxygen species metabolic process

retinoic acid metabolic process

aTP metabolic process

Figure 1- Functional distribution of proteins identified with differential expression in liver of mice belonging to $A / J$ vs. $129 \mathrm{p} 3 / \mathrm{J}$ strains. Categories of proteins based on GO annotation Biological Process. Terms significant (Kappa=0.03) and distribution according to percentage of number of genes association

explain the differential metabolic handling and effects of $F$ in these two strains. It has been shown that even without exposure to $\mathrm{F}, \mathrm{A} / \mathrm{J}$ mice present a higher retention of proteins in the maturing enamel ${ }^{9}$. For this reason, the mice were not treated with $F$, because we wanted to see differences in the liver proteome profile that were intrinsic to the strains. Most proteins with fold change were increased in the $A / J$ mice (Table 1 ), with fold changes ranging between 1 and 2 . Formimidoyltransferase-cyclodeaminase, however, was increased 3.82 times in A/J mice. This enzyme is a liver-specific antigen recognized by sera of patients with autoimmune hepatitis ${ }^{14}$ and is found down-regulated in hepatocellular carcinoma ${ }^{16}$. Formimidoyltransferase-cyclodeaminase has two enzymatic functions. In one of them, formiminotetrahydrofolate and glutamate are produced. Through its cyclodeaminase function, the enzyme breaks down formiminotetrahydrofolate, involved in the synthesis of purines and pyrimidines, and amino acids (UNIPROT). Thus, the increase in this enzyme might explain the increased expression of other liver proteins in $A / J$ mice due to higher supply of nucleotides and amino acids.

Remarkably, the functional category with the highest percentage of altered genes was oxidationreduction process. The increase of proteins such as ATP synthase subunit alpha, mitochondrial, Heat shock cognate 71 kDa protein, Electron transfer flavoprotein subunit beta, Alpha-enolase, Beta-enolase, Gamma-enolase and, Malate dehydrogenase in the $\mathrm{A} / \mathrm{J}$ mice indicate an increased energy flux in this strain, which might generate oxidative stress. This can be confirmed by the concomitant increase in GRP78, which suggests endoplasmic reticulum (ER) stress ${ }^{20}$. ER stress occurs when nascent proteins are misfolded or not folded properly, leading to the initiation of the unfolded protein response, as the unfolded proteins accumulate in the $\mathrm{ER}^{13}$. It has been demonstrated that $F$ is able to induce an ER stress response in the LS8 ameloblast-derived cell line, which could be implicated in the pathogenesis of dental fluorosis ${ }^{13}$. In addition, administration of $F$ through the drinking water is able to increase the expression of GRP78 in the liver of rats $^{20}$. Thus, considering that $A / J$ mice present an increased energy flux and tendency to oxidative stress even without exposure to $F$, this exposure has been shown to worsen oxidative stress ${ }^{20}$, which can implicate in the pathogenesis of dental fluorosis ${ }^{8}$, this can be a hypothesis for the high susceptibility of the $A / J$ to the effects of $F$.

The proteins in the center of the protein-protein interaction network are related to potassium channels. One of them (calcium-activated potassium channel subunit alpha-1) is a potassium channel activated either by membrane depolarization or increase in cytosolic $\mathrm{Ca}^{2+}$ that mediates export of $\mathrm{K}^{+}$. It is also activated by the concentration 


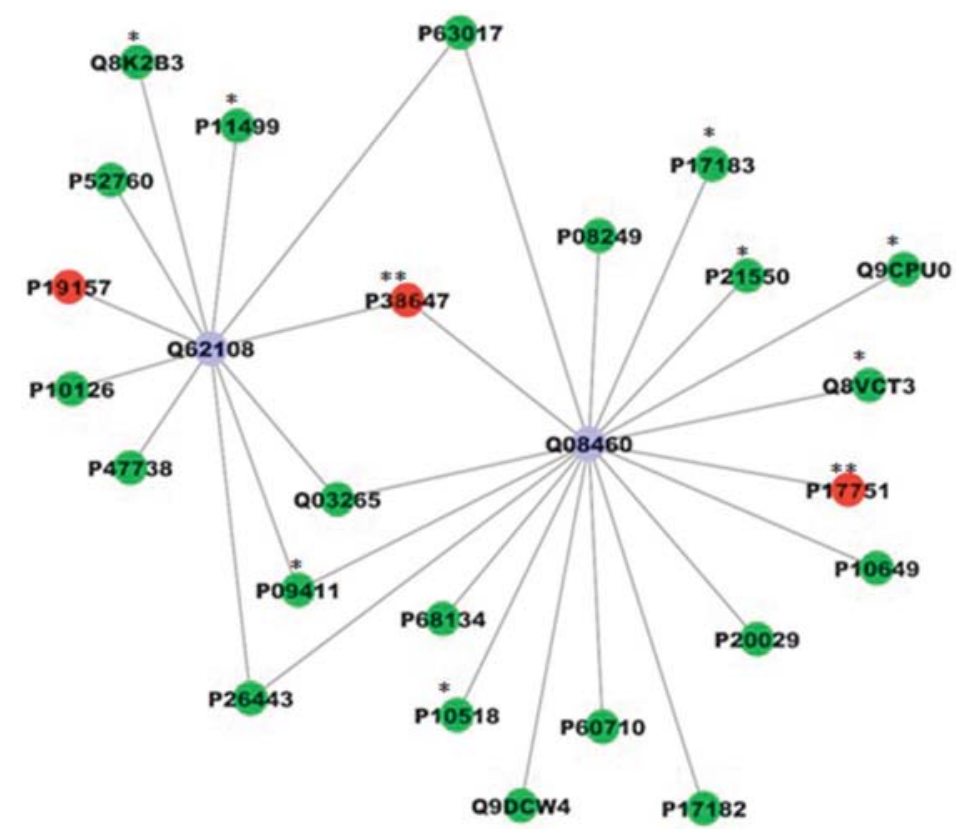

Figure 2- Subnetworks generated by VizMapper for each comparison - A Group A/J vs. 129p3/J. Color of node and * indicate the differential expression of the respective protein, for each comparison. Red and green nodes indicate protein down-regulation and up-regulation, respectively, while * and ** indicate presence and absence of protein, respectively, in the respective group. Purple node indicates proteins presenting interaction but that were not identified in the present study. The access numbers in nodes correspond to: P68134- (Acta1)Actin, alpha skeletal muscle; P10518- (Alad) Deltaaminolevulinic acid dehydratase; Q9DCW4- (Etfb) Electron transfer flavoprotein subunit beta; P60710- (Actb) Actin, cytoplasmic 1; P17182- (Eno1) Alpha-enolase; P20029- (Hspa5) 78 kDa glucose-regulated protein; P10649- (Gstm1) Glutathione S-transferase Mu 1; P17751- (Tpi1) Triosephosphate isomerase; Q8VCT3- (Rnpep) Aminopeptidase B; Q9CPU0- (Glo1) Lactoylglutathionelyase; P21550- (Eno3) Beta-enolase; P17183- (Eno2) Gamma-enolase; P08249- (Mdh2) Malate dehydrogenase; P63017- (Hspa8) Heat shock cognate; P38647- (Hspa9) Stress-70 protein; Q03265- (Atp5a1) ATP synthase subunit alpha; P09411- (Pgk1) Phosphoglycerate kinase 1; P26443- (Glud1) Glutamate dehydrogenase 1; P47738- (Aldh2) Aldehyde dehydrogenase; P10126- (Eef1a1) Elongation factor 1-alpha 1; P19157- (Gstp1) Glutathione S-transferase P 1; P52760- (Hrsp12) Ribonuclease; Q8K2B3- (Sdha) Succinate dehydrogenase; P11499- (Hsp90ab1) Heat shock protein; Q62108- (Dlg4) Disks large homolog 4; Q08460- (Kcnma1) Calcium-activated potassium channel subunit alpha-1

of cytosolic $\mathrm{Mg}^{2+}$. Its activation dampens the excitatory events that elevate the cytosolic $\mathrm{Ca}^{2+}$ concentration and/or depolarize the cell membrane. Therefore, it contributes to the repolarization of the membrane potential and plays a key role in controlling excitability in a number of systems, such as regulation of the contraction of smooth muscle ${ }^{21}$, the tuning of hair cells in the cochlea ${ }^{6}$, regulation of transmitter release ${ }^{6}$ and innate immunity ${ }^{2}$. The other one is Disks large homolog 4 that is required for synaptic plasticity associated with NMDA ( $\mathrm{N}$-methyl-D-aspartate) receptor signaling ${ }^{11}$. It interacts with shaker-type potassium channels and the cytoplasmic tail of NMDA receptor subunits. At first glance, it may seem odd the presence of a protein associated with the nervous system in the center of the network in this study. However, we must consider that liver failure leaves to the accumulation of ammonia, which affects the cerebral function ${ }^{10}$. As mentioned above, A/J mice presented several proteins related to the energy flux increased in the liver, which might have caused oxidative stress and contributed to liver damage, which in turn might have provoked cerebral alterations. Since this was a preliminary exploratory work, future studies comparing the proteomic profile of the brain of these mice strains should be conducted to add new light into this topic. Also, additional studies should be done to quantify, by other techniques, the proteins with changing expression in this study. Despite being an exploratory study, the lack of additional techniques to confirm the proteins with altered expression identified by nLC-MS/MS might be considered a limitation of this study.

\section{CONCLUSIONS}

In conclusion, $A / J$ mice had an increase in proteins related to energy flux and oxidative stress. This could be a possible explanation for the high susceptibility of these mice to the effects of $F$, since 
F exposure also induces oxidative stress.

\section{ACKNOWLEDGMENTS}

The authors thank CNPq/TWAS for granting the scholarship to the first author.

\section{CONFLI CT OF I NTEREST STATEMENT}

The authors have declared no conflict of interest.

\section{REFERENCES}

1- Bauer-Mehren A. Integration of genomic information with biological networks using Cytoscape. Methods Mol Biol. 2013;1021:37-61.

2- Butler A, Tsunoda S, McCobb DP, Wei A, Salkoff L. mSlo, a complex mouse gene encoding "maxi" calcium-activated potassium channels. Science. 1993;9;261(5118):221-4.

3- Bradford MM. A rapid and sensitive method for the quantitation of microgram quantities of protein utilizing the principle of proteindye binding. Anal Biochem. 1976;72: 248-54.

4- Carvalho JG, Leite AL, Peres-Buzalaf C, Salvato F, Labate $\mathrm{CA}$, Everett $\mathrm{ET}$, et al. Renal proteome in mice with different susceptibilities to fluorosis. PLoS One. 2013;8(1):e53261.

5- Carvalho JG, Leite AL, Yan D, Everett ET, Whitford GM, Buzalaf MA. Influence of genetic background on fluoride metabolism in mice. J Dent Res. 2009;88(11):1054-8.

6- Cabo R, Zichichi R, Viña E, Guerrera MC, Vázquez G, GarcíaSuárez $\mathrm{O}$, et al. Calcium-activated potassium channel SK1 is widely expressed in the peripheral nervous system and sensory organs of adult zebrafish. Neurosci Lett. 2013;25;555:62-7.

7- Charone S, Leite AL, Peres-Buzalaf C, Fernandes MS, Almeida LF, Graeff MS, et al. Proteomics of secretory and maturation stage enamel of genetically distinct mice. Caries Res. 2016;50:24-31. 8- Everett ET, McHenry MA, Reynolds N, Eggertsson H, Sullivan J, Kantmann C, et al. Dental fluorosis: variability among different inbred mouse strains. J Dent Res. 2002;81(11):794-8.

9- Everett ET, Yan D, Weaver M, Liu L, Foroud T, Martinez-Mier EA. Detection of dental fluorosis-associated quantitative trait Loci on mouse chromosomes 2 and 11 . Cells Tissues Organs. 2009;189(1-4):212-8.
10- Felipo V. Hepatic encephalopathy: effects of liver failure on brain function. Nat Rev Neurosci. 2013;14(12):851-8.

11- Halff AW, Gómez-Varela D, John D, Berg DK. A nove mechanism for nicotinic potentiation of glutamatergic synapses. J Neurosci. 2014;5;34(6):2051-64.

12- Kobayashi CA, Leite AL, Peres-Buzalaf C, Carvalho JG, Whitford $\mathrm{GM}$, Everett $\mathrm{ET}$, et al. Bone response to fluoride exposure is influenced by genetics. PLoS One. 2014;11;9(12):e114343.

13- Kubota K, Lee DH, Tsuchiya M, Young CS, Everett ET, MartinezMier EA, et al. Fluoride induces endoplasmic reticulum stress in ameloblasts responsible for dental enamel formation. J Biol Chem. 2005;280(24):23194-202.

14- Lapierre P, Hajoui O, Homberg JC, Alvarez, F. Formiminotransferase cyclodeaminase is an organ-specific autoantigen recognized by sera of patients with autoimmune hepatitis. Gastroenterology. 1999;116:643-9.

15- Leite AL, Lobo GV, Pereira HA, Fernandes MS, Martini T, Zucki $F$, et al. Proteomic analysis of gastrocnemius muscle in rats with streptozotocin-induced diabetes and chronically exposed to fluoride. PLoS One. 2014;9(9):e106646.

16- Liang CR, Leow CK, Neo JC, Tan GS, Lo SL, Lim JW, et al. Proteome analysis of human hepatocellular carcinoma tissues by two-dimensional difference gel electrophoresis and mass spectrometry. Proteomics. 2005;5(8)2258-71.

17- Lobo JG, Leite AL, Pereira HA, Fernandes MS, Peres-Buzalaf C, Sumida DH, et al. Low-level fluoride exposure increases insulin sensitivity in experimental diabetes. J Dent Res. 2015;94(7):9907.

18- Millan PP. Visualization and analysis of biological networks. Methods Mol Biol. 2013;1021: 63-88.

19- Orchard S. Molecular interaction databases. Proteomics. 2012;12(10):1656-62.

20- Pereira HA, Leite AL, Charone S, Lobo JG, Cestari TM, PeresBuzalaf $C$, et al. Proteomic analysis of liver in rats chronically exposed to fluoride. PLoS One. 2013;8(9):e75343.

21- Sánchez-Pastor E, Andrade F, Sánchez-Pastor JM, Elizalde A, Huerta M, Virgen-Ortiz A, et al. Cannabinoid receptor type 1 activation by arachidonylcyclopropylamide in rat aortic rings causes vasorelaxation involving calcium-activated potassium channel subunit alpha-1 and calcium channel, voltage-dependent, L type, alpha 1C subunit. Eur J Pharmacol. 2014;15(729):100-6. 22- Taves DR. Separation of fluoride by rapid diffusion using hexamethyldisiloxane. Talanta. 1968;15(9):969-74. 